\title{
Do Factors Implied in Dividend Discount Models Really Affect Price-Earnings Ratios in Chinese Stock Market?
}

\author{
Jingying Zhou \\ Yunnan Research Institute of Finance Innovation \\ Kunming,China \\ zhoujy1030@hotmail.com
}

\begin{abstract}
Price-Earnings ratio (P/E ratio) is frequently utilized to evaluate a stock. Determining what factors have influences on $\mathbf{P} / \mathbf{E}$ ratios is beneficial to better interpretation and prediction of this ratio in practice. Historically, though some academic studies on this topic have identified some factors in terms of both microeconomics and macroeconomics, many of them were conducted in developed financial markets decades ago. This article proceeds with a combination of well-developed theoretical foundation and empirical studies in emerging market using latest data. It begins with traditional value theories and identifies three potential factors: dividend payout ratios, earnings growth rates and Beta coefficient. Then updated data from Chinese stock market are collected and analyzed to further find out the relationship. Behavior patterns of these three factors are also examined to check if there exists certain degree of persistence over time. When coping with earnings growth rates, we take non-recurring items into consideration. In the last and the most important part, regression analysis is carried out to give insights on the magnitude of significance of the relationship.
\end{abstract}

Keywords-P/E ratios; dividend payout ratios; Beta coefficient; earnings growth rates; non-recurring items

\section{INTRODUCTION}

Price-Earnings ratio, called $\mathrm{P} / \mathrm{E}$ ratio for short, is undoubtedly one of the most popular tools for stock pricing. It also plays an important role to determine if the value of an investment or even a market is inflated. Appropriate measurement, interpretation and prediction of $\mathrm{P} / \mathrm{E}$ ratio make vast contribution to wise judgements towards potential investment opportunities. Although $\mathrm{P} / \mathrm{E}$ ratio can be calculated via dividing a stock's price by its earning, determining and interpreting what factors driving it dynamically are not an easy task. A number of scholars and researchers have conducted a series of empirical studies on this problem and both micro and macro factors have been identified. Reilly, Griggs and Wong have collected quarterly data of S\&P 400 Index during 19621980 and regressed $\mathrm{P} / \mathrm{E}$ ratio against business cycle factor as well as coefficient of dispersion for EPS, then they have proved that the relationships are insignificant [1]. Using real interest rate, inflation rate and dividend payout ratio as independent variables, Kane, Marcus and Noh carry out a regression analysis based on market index data from 1954 to 1993 and conclude that the first two factors have negative correlations with $\mathrm{P} / \mathrm{E}$ ratio while the last one indicates a positive linkage [2].

Many of these studies are rooted in developed markets and the data they use are out-of-date. To better provide updated insight into this problem, we build our analysis in the setting of emerging market. In the following parts, we revisit some traditional valuation models and then take empirical studies in the basis of latest data from Chinese stock market.

\section{VALUATION THEORIES}

In a perfect financial market, Discount Dividend Models (DDM) usually provide an efficient way to link a stock's intrinsic value to several variables, therefore they are revisited to find out the linkage.

\section{A. Single-stage DDM: Gordon Growth Model}

Gordon Growth Model (GGM) is the most prestigious Discount Dividend Model. Developed by M. Gordon, GGM discounts a stream of dividends flows back to the present to get a stock's intrinsic value [3]. Basically, GGM is based on two assumptions: 1.The growth rates of dividends paid out to shareholders remain constant. 2. The required return which is also the discount rate in denominator must be larger than the dividend growth rate, thus avoiding generating illogical negative figures. The share price given by GGM is as below, which is the sum of a geometric sequence:

$$
P_{0}=\frac{D_{0} \times\left(1+g_{d}\right)}{(1+R)}+\frac{D_{0} \times\left(1+g_{d}\right)^{2}}{(1+R)^{2}}+\frac{D_{0} \times\left(1+g_{d}\right)^{3}}{(1+R)^{3}}+\cdots+\frac{D_{0} \times\left(1+g_{d}\right)^{n}}{(1+R)^{n}}
$$

Note:

$\mathrm{P}_{0}=$ stock price at time $0 ; \mathrm{D}_{0}=$ dividend at time $0 ; \mathrm{g}_{\mathrm{d}}=$ constant level of dividend growth rate; $\mathrm{R}=$ required rate of return

Applying the summation rule for geometric sequence, Equation (1) can be consolidated as:

$$
\mathrm{P}_{0}=\frac{\mathrm{D}_{0} \times\left(1+\mathrm{g}_{\mathrm{d}}\right)}{\mathrm{R}-\mathrm{g}}
$$

If we expand the first assumption to also include a constant dividend payout ratio $b$, then the growth rate of earnings should be equal to the growth rate of dividend ge. As a result, Equation (2) can be presented as: 


$$
\mathrm{P}_{0}=\frac{\mathrm{E}_{0} \times \mathrm{b} \times\left(1+\mathrm{g}_{\mathrm{d}}\right)}{\mathrm{R}-\mathrm{g}}
$$

If both sides of the Equation (3) are divided by earnings at time 0 (denoted as E0), then a company's trailing $\mathrm{P} / \mathrm{E}$ ratio is given as:

$$
\frac{\mathrm{P}_{0}}{\mathrm{E}_{0}}=\frac{\mathrm{b} \times\left(1+\mathrm{g}_{\mathrm{d}}\right)}{\mathrm{R}-\mathrm{g}}
$$

According to mathematical rules, intuitively, it can be concluded from Equation (3) that $\mathrm{P} / \mathrm{E}$ ratio correlates positively with earnings growth rate ge and dividend payout ratio $b$, and inversely with required rate of return $\mathrm{R}$.

\section{B. Multi-stage DDM: H-model}

Gordon Growth Model has a major drawback, since it is extremely unrealistic to assume a perpetual constant growth rate. Several multi-stage models have been developed to modify this weakness, and H-model is one of them [4]. $\mathrm{H}-$ model divides growth stages into multiple stages, usually containing rapid ones and a stable one. When compared with other multi-stage models, the H-model does not assume an immediate drop to stable growth rates, but instead, it declares that over the first rapid-growing stage, growth rates gradually decrease linearly to stable growth rate. With a constant dividend payout ratio $b$ as assumed before, the basic two-stage $\mathrm{H}$-model sums both the value of rapid stage $\mathrm{V} 1$ and value of second stable stage V2.

$$
\begin{gathered}
\mathrm{P}_{0}=\mathrm{V}_{1}+\mathrm{V}_{2}=\frac{\mathrm{E}_{0} \times \mathrm{b} \times\left(1+\mathrm{g}_{\mathrm{L}}\right)}{\mathrm{r}-\mathrm{g}_{\mathrm{L}}}+\frac{\mathrm{E}_{0} \times \mathrm{b} \times \mathrm{t} / 2 \times\left(\mathrm{g}_{\mathrm{H}}-\mathrm{g}_{\mathrm{L}}\right)}{\mathrm{r}-\mathrm{g}_{\mathrm{L}}} \\
\frac{\mathrm{P}_{0}}{\mathrm{E}_{0}}=\frac{\mathrm{b} \times\left(1+\mathrm{g}_{\mathrm{L}}\right)}{\mathrm{r}-\mathrm{g}_{\mathrm{L}}}+\frac{\mathrm{b} \times \mathrm{t} / 2 \times\left(\mathrm{g}_{\mathrm{H}}-\mathrm{g}_{\mathrm{L}}\right)}{\mathrm{r}-\mathrm{g}_{\mathrm{L}}}
\end{gathered}
$$

Note:

$\mathrm{g}_{\mathrm{H}}=$ rapid growth rate in the first stage which lasts for $\mathrm{m}$ years;

$\mathrm{g}_{\mathrm{L}}=$ sustainable growth rate in the second stage;

$\mathrm{t}=$ the length of first stage

When compared to Equation (3), although Equation (6) introduces additional growth rate, it does not exert any change on the directions of interaction between $\mathrm{P} / \mathrm{E}$ ratios and the three factors as mentioned earlier. All of the growth rates in $\mathrm{H}$-model still have positive relationship with $\mathrm{P} / \mathrm{E}$ ratios.

Notably, the required rate of return $\mathrm{R}$ represents $\mathrm{a}$ minimum level of compensation, demanded by investors, for occupation and utilization of their capital. It is also regarded as a compensation for taking risk and is crucial for investors to evaluate an investment. Expected required rate of return can be derived by Capital Asset Pricing Model (CAPM) developed by William. Sharpe. [5] This Nobel Prize winning model provides an intuitive bridge between expected return and systematic risk.

$$
\begin{gathered}
E\left(r_{i}\right)=r_{f}+\beta \times\left(E\left(r_{m}\right)-r_{f}\right) \\
\beta=\frac{\operatorname{Cov}\left(r_{m}, r_{i}\right)}{\sigma_{m}^{2}}
\end{gathered}
$$

Note: $\mathrm{r}_{\mathrm{f}}=$ risk free rate; $\mathrm{E}\left(\mathrm{r}_{\mathrm{m}}\right)=$ expected return of market; $\mathrm{r}_{\mathrm{m}}=$ return of market; $r_{i}=$ return of individual stock; $\sigma_{\mathrm{m}}=$ standard deviation of market return $r_{m}$

According to CAPM, same risk free rate and return of market apply to all enterprises in the same jurisdiction, thus Beta coefficient $(\beta)$ is the only factor explaining differences in required rates of return. Beta provides a way to measure the level of individual stock's sensitivity to systematic risk which is imposed by the broad market and cannot be diversified away. As indicated, Beta is the slope of the line SML draw derived from CAPM and has a positive relationship with $\mathrm{R}$. Therefore, based on DDM, three factors that influence the level of $\mathrm{P} / \mathrm{E}$ ratios can be identified: earnings growth rates, dividend payout ratios and Beta. The relationship implied in the theories can be stated as: higher growth potential, higher dividend payout ratio and lower Beta all contribute to higher relative price represented as $\mathrm{P} / \mathrm{E}$ ratio.

However, though relationship is explicit in theory, real world may tell a completely different story. Reality is considerably more complicated than valuation theories. Assumptions underlying those models are no longer valid and inputs such as b, R and ge are themselves influenced by many transitory factors, such as policy changes and emotional biases. These stochastic factors are likely to distort the nature in each of this inputs. Another non-negligible fact is that, these input, when used in practice, must be measured and estimated, which inevitably is a process with subjectivity and errors [6]. All of these uncertainties may create complication and distortion.

\section{DATA AND EMPIRICAL STUDIES}

The empirical studies have a time span of ten years, covering from 2007 to 2016, accordingly, earnings data and stock prices are collected from Wind during this period, with extra price data from 2017 also involved to form the P/E ratio in 2016. We collect data of a stock pool, which contains all 1,285 domestic stocks that once listed or are now listing in Shanghai Stock Exchange. These stocks are referred as "A" stocks, which are quoted and traded in Chinese yuan, while "B" stocks are also quoted in Chinese yuan but traded in dollars. Selection of this universe can be justified. This stock pool contains more than one thousand stock with no particular industry, style or market capitalization biases, and its corresponding index Shanghai Composite Index is highly recognized as the broad market benchmark across different users, including policy makers, regulators, institutional investors and individual investors.

To calculate a stock's trailing P/E ratio, we use basic EPS and prices on the last calendar day of March, that is, March 31 st. If this date happens to be non-business day, then we move one day backward until we have a business day. Technically, at least one day of March 29th, 30th and 31st fulfils our requirements. The rationale for choosing end-ofMarch date is that stock prices on that day usually fully reflect performance from previous year but are scarcely affected by new information from the first quarter; on this date, most public companies have already released their annual reports or preannouncements but have not presented the first quarter performance yet. In order to make the analysis efficient, 
objective and unbiased, we need to exclude all unqualified stocks that fall into any of the following two categories. The first category is stocks which are suspended, delisted or have not listed yet on the chosen end-of-March date in any of these 11 years, since no prices are available to calculate $\mathrm{P} / \mathrm{E}$ ratios. The second one contains stocks with negative basic EPS during any year of our analysis scope, since these stocks will have negative $\mathrm{P} / \mathrm{E}$ ratios which lead to incomparability. After the exclusion, we retain 212 eligible stocks. In order to divide into more equally sized groups, we randomly eliminate two stocks, thus 210 sample stocks remain.

Based on these stocks' $\mathrm{P} / \mathrm{E}$ ratios in the base year 2007, we rank and then divide them into five groups, each consisting of 42 stocks. These groups are labeled from Group 1 to Group 5, with Group 1 containing first 42 highest P/E-ratio stocks and Group 5 containing 42 lowest P/E-ratio stocks. To remove effects from outliers, we calculate the median rather than the mean to capture average level of each group in a particular year. Tab.I provides a statistic summary.

table I. Summary of Median P/E Ratios During Last Ten YEARS (2007 TO 2016)

\begin{tabular}{|c|c|c|c|c|c|}
\hline Group No. & $\mathbf{1}$ & $\mathbf{2}$ & $\mathbf{3}$ & $\mathbf{4}$ & $\mathbf{5}$ \\
\hline $\mathbf{2 0 0 7}$ & 117.71 & 51.70 & 37.20 & 27.71 & 19.44 \\
\hline $\mathbf{2 0 0 8}$ & 57.96 & 30.29 & 31.51 & 25.97 & 21.92 \\
\hline $\mathbf{2 0 0 9}$ & 74.30 & 40.75 & 38.47 & 38.14 & 23.54 \\
\hline $\mathbf{2 0 1 0}$ & 60.18 & 38.21 & 32.91 & 27.78 & 20.36 \\
\hline $\mathbf{2 0 1 1}$ & 35.68 & 24.72 & 19.00 & 19.73 & 13.03 \\
\hline $\mathbf{2 0 1 2}$ & 40.64 & 23.53 & 23.54 & 19.25 & 14.60 \\
\hline $\mathbf{2 0 1 3}$ & 47.19 & 23.06 & 21.95 & 20.88 & 12.52 \\
\hline $\mathbf{2 0 1 4}$ & 77.35 & 36.61 & 38.73 & 35.45 & 21.94 \\
\hline $\mathbf{2 0 1 5}$ & 77.10 & 33.43 & 35.15 & 29.02 & 18.52 \\
\hline $\mathbf{2 0 1 6}$ & 84.88 & 34.62 & 31.33 & 27.32 & 24.47 \\
\hline
\end{tabular}

In the base year 2007 , medians of $\mathrm{P} / \mathrm{E}$ ratios cover a wide range from 117.71 to 19.44 , implying the median $\mathrm{P} / \mathrm{E}$ ratio in Group 1 is approximately 6 times of that in Group 15. Medians drop at a considerable rate from Group 1 to Group 2, then slow down and decrease at a relatively stable rate across subsequent groups. A certain degree of persistence can also be found in subsequent years. For example, Group 1's median $\mathrm{P} / \mathrm{E}$ ratios still rank the first in all of the subsequent years.

\section{A. Degree of Persistence for P/E ratios Across Years}

To further investigate the persistence over time, we expand our research to the whole series of data and report the results in Tab. 2.

TABLE II. CORRELATIONS MATRIX OF P/E RATIOS

\begin{tabular}{|l|l|l|l|l|l|l|l|l|l|}
\hline $\begin{array}{c}\text { Base } \\
\text { year }\end{array}$ & \multicolumn{10}{|c|}{ Number of Years Following Base Years } \\
\hline & $\mathbf{1}$ & $\mathbf{2}$ & $\mathbf{3}$ & $\mathbf{4}$ & $\mathbf{5}$ & $\mathbf{6}$ & $\mathbf{7}$ & $\mathbf{8}$ & $\mathbf{9}$ \\
\hline $\mathbf{2 0 0 7}$ & 0.23 & 0.25 & 0.31 & 0.12 & 0.10 & 0.10 & 0.16 & 0.08 & 0.13 \\
\hline $\mathbf{2 0 0 8}$ & 0.40 & 0.21 & 0.13 & 0.20 & 0.20 & 0.33 & 0.09 & 0.15 & \\
\hline $\mathbf{2 0 0 9}$ & 0.38 & 0.42 & 0.72 & 0.72 & 0.77 & 0.32 & 0.45 & & \\
\hline $\mathbf{2 0 1 0}$ & 0.52 & 0.27 & 0.26 & 0.17 & 0.13 & 0.24 & & & \\
\hline
\end{tabular}

\begin{tabular}{|l|l|l|l|l|l|l|l|l|l|}
\hline $\mathbf{2 0 1 1}$ & 0.44 & 0.41 & 0.28 & 0.25 & 0.39 & & & & \\
\hline $\mathbf{2 0 1 2}$ & 0.99 & 0.46 & 0.47 & 0.13 & & & & & \\
\hline $\mathbf{2 0 1 3}$ & 0.47 & 0.47 & 0.62 & & & & & & \\
\hline $\mathbf{2 0 1 4}$ & 0.23 & 0.23 & & & & & & & \\
\hline $\mathbf{2 0 1 5}$ & 0.53 & & & & & & & & \\
\hline
\end{tabular}

Every result in Tab. 3 corresponds to the correlation coefficient between a $\mathrm{P} / \mathrm{E}$ ratio data series from a base year and that from a subsequent year "n" years away the base year. For example, the upper-right cell data 0.13 is the correlation between $\mathrm{P} / \mathrm{E}$ ratios in 2007 and those from 2016, nine years subsequent to 2007. When group effects are not taken account, the results do exhibit positive relationship, but the magnitudes of correlation vary significantly across different pairs of data, with a maximum of 0.99 and a minimum closer to zero.

Before moving on to examine the relation between $\mathrm{P} / \mathrm{E}$ ratio and the three factors, we take glimpse on how these factors themselves behave. Basically, just as what we have done with $\mathrm{P} / \mathrm{E}$ ratios above, we use correlation matrix on medians. Besides, we add grouping effects into the analysis of earning growth rates.

\section{B. Behavior Patterns of Dividend Payout Ratios and Beta over Time}

Although all of the sample companies report positive earnings (we have excluded those companies with negative basic EPS) during these ten years, some choose not to distribute dividends due to expansion opportunities or other consideration. Even among companies which pay dividends, the payout ratios vary remarkably because of different payout polices, such as constant amount per share or constant proportion to earnings.

TABLE III. CORRELATIONS MATRIX OF DIVIDEND PAYOUTT RATIOS

\begin{tabular}{|c|c|c|c|c|c|c|c|c|c|}
\hline $\begin{array}{c}\text { Base } \\
\text { year }\end{array}$ & \multicolumn{10}{|c|}{ Number of Years Following Base Years } \\
\hline & $\mathbf{1}$ & $\mathbf{2}$ & $\mathbf{3}$ & $\mathbf{4}$ & $\mathbf{5}$ & $\mathbf{6}$ & $\mathbf{7}$ & $\mathbf{8}$ & $\mathbf{9}$ \\
\hline $\mathbf{2 0 0 7}$ & 0.16 & 0.45 & 0.55 & 0.42 & 0.05 & 0.26 & 0.18 & 0.20 & 0.29 \\
\hline $\mathbf{2 0 0 8}$ & 0.12 & 0.12 & 0.06 & 0.01 & 0.09 & 0.03 & 0.07 & 0.04 & \\
\hline $\mathbf{2 0 0 9}$ & 0.50 & 0.49 & 0.19 & 0.36 & 0.51 & 0.30 & 0.28 & & \\
\hline $\mathbf{2 0 1 0}$ & 0.70 & 0.10 & 0.74 & 0.24 & 0.25 & 0.72 & & & \\
\hline $\mathbf{2 0 1 1}$ & 0.48 & 0.42 & 0.26 & 0.27 & 0.26 & & & & \\
\hline $\mathbf{2 0 1 2}$ & 0.31 & 0.36 & 0.10 & 0.08 & & & & & \\
\hline $\mathbf{2 0 1 3}$ & 0.36 & 0.39 & 0.83 & & & & & & \\
\hline $\mathbf{2 0 1 4}$ & 0.35 & 0.31 & & & & & & & \\
\hline $\mathbf{2 0 1 5}$ & 0.56 & & & & & & & & \\
\hline
\end{tabular}

It can be observed from Tab. 3 that no manifest persistence exists in dividend payout ratios, thus dividend payout policies are subjected to numerous transitory factors. Therefore, in China, public companies tend to pay less attention on the maintaining stable dividend payout ratios.

Then we focus on Beta coefficients. Unlike dividend payout ratios, Beta is less vulnerable to changing strategies from arbitrary management. According to Equation (8), we calculate daily returns for all of the 200 stocks and broad 
market over the past ten years and then derive Beta coefficients of these individual stocks each year.

TABLE IV. CORRElations Matrix OF BetA

\begin{tabular}{|c|c|c|c|c|c|c|c|c|c|}
\hline & \multicolumn{7}{|c|}{ Number of Years Following Base Years } \\
\hline $\begin{array}{l}\text { Base } \\
\text { year }\end{array}$ & $\mathbf{1}$ & $\mathbf{2}$ & $\mathbf{3}$ & $\mathbf{4}$ & $\mathbf{5}$ & $\mathbf{6}$ & $\mathbf{7}$ & $\mathbf{8}$ & $\mathbf{9}$ \\
\hline $\mathbf{2 0 0 7}$ & 0.59 & 0.54 & 0.37 & 0.32 & 0.29 & 0.28 & 0.28 & 0.32 & 0.21 \\
\hline $\mathbf{2 0 0 8}$ & 0.74 & 0.47 & 0.45 & 0.43 & 0.38 & 0.28 & 0.32 & 0.35 & \\
\hline $\mathbf{2 0 0 9}$ & 0.64 & 0.53 & 0.49 & 0.46 & 0.30 & 0.32 & 0.30 & & \\
\hline $\mathbf{2 0 1 0}$ & 0.59 & 0.59 & 0.46 & 0.41 & 0.33 & 0.27 & & & \\
\hline $\mathbf{2 0 1 1}$ & 0.67 & 0.40 & 0.21 & 0.25 & 0.42 & & & & \\
\hline $\mathbf{2 0 1 2}$ & 0.54 & 0.34 & 0.29 & 0.49 & & & & & \\
\hline $\mathbf{2 0 1 3}$ & 0.56 & 0.25 & 0.28 & & & & & & \\
\hline $\mathbf{2 0 1 4}$ & 0.31 & 0.14 & & & & & & & \\
\hline $\mathbf{2 0 1 5}$ & 0.48 & & & & & & & & \\
\hline
\end{tabular}

Beta series exhibits a far more obvious and stable level of persistence and this kind of persistence fades away as Beta series is compared with peers from more distant years. For example, if we take the year 2008 as base year and choose another comparison year, we will find out that, the more distant the comparison year is, the less significant the figure becomes. The correlation coefficient drops from 0.74 for 2008-2009 pair to a less significant level of 0.27 for 20082016 pair.

\section{Behavior Patterns of Unadjusted and Adjusted Earnings Growth Rates Across Groups}

EPS are vulnerable to affects from stock dividends and splits, therefore, they are replaced by total earnings to derive growth rates. Two forms of earnings are collected, that is, net incomes before and after adjusting non-recurring items. Normally, non-recurring items include one-time items such as proceeds from sales of equipments and government subsidies and are deemed as stochastic and a main contributor to unpredictability of future earnings. Consequently, they may obscure the implied patterns which could be discovered. One the other hand, though with more flaws and criticism, earnings including non-recurring items are more frequently adopted to interpret and forecast enterprises' operating performance, thus by no means will they be bypassed in our study.

We derive medians for both kinds of earnings, depict line charts in groups and exhibit the results in Fig.1 and Fig. 2 .

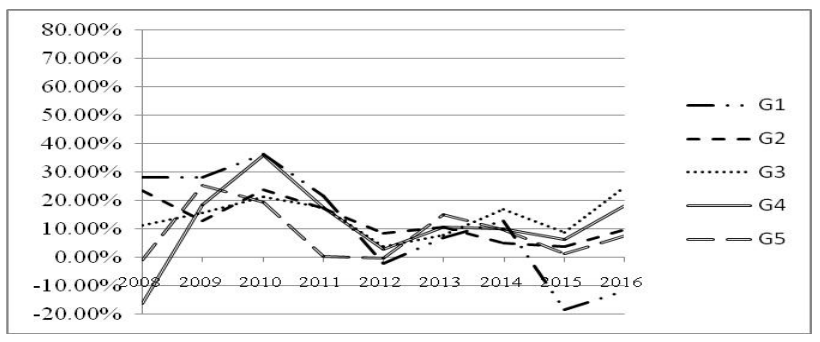

Fig. 1. Patterns of changes of unadjusted earnings growth rates.

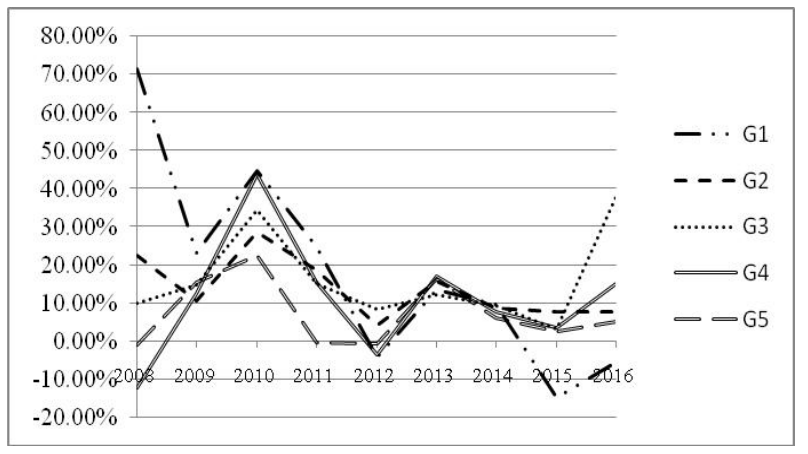

Fig. 2. Patterns of changes of unadjusted earnings growth rates

No explicit evidence for constancy across years could be found, since there is a manifestation of drastic variations over time under both circumstances. Also, we cannot declare clear relations between $\mathrm{P} / \mathrm{E}$ ratios and growth rates. For instance, in Fig. I(B), Group 1, made up of stocks with first 42 highest $\mathrm{P} / \mathrm{E}$ ratios, has an impressive median adjusted earnings growth rate of over $70 \%$ which is more than twice of medians from other groups. If high growth rates are somewhat persistent and correlated with high $\mathrm{P} / \mathrm{E}$ ratios, then this remarkable level of growth rates is expected to continue, however, Group 1's line acts the opposite. Despite fluctuations, it then plummets and, in 2015, reaches the point of the minimum. But figures depicted above reveal an interesting phenomenon: different groups' lines show a tendency of co-movement, therefore which the directions of changes for growth rates tend to be consistent among the five groups. This pattern of comovement is also clearer in Fig. 2 , where non-recurring items are removed from earnings.

\section{Regression Analysis}

After analyzing idividual factors, we examine the aggregate effects of these three factors by regressing $\mathrm{P} / \mathrm{E}$ ratios on them. Considering the fact that adjusted earnings are less likely to exposed to manipulation and artificial inflation and our previous study also reveals that adjusted growth rates present a more manefest co-moving pattern, we drop unadjusted earnings growth return in our regression analysis and retain only adjusted ones. With $\alpha 0$ as the intercept and $\alpha$ $1, \alpha 2$ and $\alpha 3$ representing coeffients for independent variables dividend payout ratio $b$, Beta and adjusted earnings growth rates $\mathrm{g}$ respectively, we constrcut the regression as below.

$$
\frac{P}{E_{t}}=\alpha_{0}+\alpha_{1} \times b_{t}+\alpha_{2} \times \beta_{t}+\alpha_{3} \times g_{t}+\varepsilon
$$

At first, to check if differences of significance exist across different levels of $\mathrm{P} / \mathrm{E}$ ratios, we regress in groups. We select three groups, Group 1, 3 and 5. These groups contain high, middle and low levels of $\mathrm{P} / \mathrm{E}$ ratios. We conduct analysis for years with even number such as 2010 , then we get five-year results and exhibit in Tab.V(A),V(B) and V (C). 
TABLE V. Egression Result With Group Effects(A) Group1

\begin{tabular}{|c|c|c|c|c|c|}
\hline Group 1 & \multicolumn{5}{|c|}{ Coefficients } \\
\hline Year & $\boldsymbol{\alpha}_{\mathbf{0}}$ & $\boldsymbol{\alpha}_{\mathbf{1}}$ & $\boldsymbol{\alpha}_{\mathbf{2}}$ & $\boldsymbol{\alpha}_{\mathbf{3}}$ & $\begin{array}{c}\text { Adjusted } \\
\mathbf{R}^{\mathbf{2}}\end{array}$ \\
\hline $\mathbf{2 0 0 8}$ & 159.99 & 2.54 & -57.21 & -2.62 & $3.87 \%$ \\
\hline $\mathbf{2 0 1 0}$ & -194.11 & $161.87 * *$ & 250.66 & -1.59 & $10.31 \%$ \\
\hline $\mathbf{2 0 1 2}$ & 159.67 & $-682.61 * *$ & 110.68 & -24.79 & $8.17 \%$ \\
\hline $\mathbf{2 0 1 4}$ & -271.26 & -236.03 & $612.30 * * *$ & $-147.71 * *$ & $32.40 \%$ \\
\hline $\mathbf{2 0 1 6}$ & -215.34 & $284.90 * * *$ & 229.51 & 2.55 & $28.97 \%$ \\
\hline
\end{tabular}

TABLE VI. GROUP 3

\begin{tabular}{|r|c|c|c|c|c|}
\hline Group 3 & \multicolumn{5}{|c|}{ Coefficients } \\
\hline Year & $\boldsymbol{\alpha}_{\mathbf{0}}$ & $\boldsymbol{\alpha}_{\mathbf{1}}$ & $\boldsymbol{\alpha}_{\mathbf{2}}$ & $\boldsymbol{\alpha}_{\mathbf{3}}$ & $\begin{array}{c}\text { Adjusted } \\
\mathbf{R}^{\mathbf{2}}\end{array}$ \\
\hline $\mathbf{2 0 0 8}$ & $271.79 * *$ & $57.92^{* * *}$ & $-193.42^{*}$ & $-144.96^{* * *}$ & $58.98 \%$ \\
\hline $\mathbf{2 0 1 0}$ & $153.37^{*}$ & -136.70 & -56.31 & -8.40 & $3.01 \%$ \\
\hline $\mathbf{2 0 1 2}$ & $34.88^{*}$ & 12.80 & -5.64 & -9.82 & $-1.19 \%$ \\
\hline $\mathbf{2 0 1 4}$ & $71.05^{*}$ & 85.77 & -27.19 & -8.34 & $-0.25 \%$ \\
\hline $\mathbf{2 0 1 6}$ & 49.71 & -130.24 & 56.48 & -11.88 & $-3.66 \%$ \\
\hline
\end{tabular}

TABLE VII. GROUP 5

\begin{tabular}{|c|c|c|c|c|c|}
\hline Group 3 & \multicolumn{5}{|c|}{ Coefficients } \\
\hline Year & $\boldsymbol{\alpha}_{\mathbf{0}}$ & $\boldsymbol{\alpha}_{\mathbf{1}}$ & $\boldsymbol{\alpha}_{\mathbf{2}}$ & $\boldsymbol{\alpha}_{\mathbf{3}}$ & Adjusted R $^{\mathbf{2}}$ \\
\hline $\mathbf{2 0 0 8}$ & 104.72 & -60.10 & -53.64 & $-55.57 * * *$ & $13.13 \%$ \\
\hline $\mathbf{2 0 1 0}$ & 21.20 & -67.48 & 31.46 & $-27.16^{*}$ & $8.11 \%$ \\
\hline $\mathbf{2 0 1 2}$ & -30.21 & $103.68 * * *$ & 12.46 & -0.41 & $67.54 \%$ \\
\hline $\mathbf{2 0 1 4}$ & 1.93 & $80.53 * * *$ & 10.94 & -4.40 & $44.48 \%$ \\
\hline $\mathbf{2 0 1 6}$ & -92.15 & -6.21 & 117.99 & $-0.39 *$ & $1.10 \%$ \\
\hline
\end{tabular}

In above tables, the asterisk symbols "**, “**” and “***" indicate that an coefficient is significant at a level of $10 \%, 5 \%$ and $1 \%$. The more asterisks there are, the more significant this coefficient is. Several conclusion can be arrived as follows. Firstly, generally speaking, the majority of these coefficients and adjusted R-square in all of the three tables from regression are not significant, indicating that this linear multi-factor model does not provide a strong explanation to $\mathrm{P} / \mathrm{E}$ ratios from each group. However, it can be observed in Tab.V(B) that all of the coefficients are exceptionally significant in 2008 and the adjusted R-square also reaches a moderate level of $58.98 \%$ Secondly, data from different groups show different level of significance for the same independent variables in the same year, thus there are no similar pattern among these three groups. Thirdly, with only one exception in Tab.V(A), all regressed coefficients of adjusted earnings growth rates are negative, some of which are also significant, implying that $\mathrm{P} / \mathrm{E}$ ratios are likely to have negative relation with adjusted growth rates, which is in inconsistent with what GGM and H-Model tell us.
Then we remove effects from groups and regress all data we have collected to inspect further.

TABLE VIII. REGRESSION RESUlts Without GROUP EFFECTS

\begin{tabular}{|c|c|c|c|c|c|}
\hline & \multicolumn{5}{|c|}{ Coefficients } \\
\hline Year & $\boldsymbol{\alpha}_{0}$ & $\boldsymbol{\alpha}_{\mathbf{1}}$ & $\boldsymbol{\alpha}_{\mathbf{2}}$ & $\boldsymbol{\alpha}_{\mathbf{3}}$ & $\begin{array}{c}\text { Adjusted } \\
\mathbf{R}^{\mathbf{2}}\end{array}$ \\
\hline $\mathbf{2 0 0 8}$ & 29.81 & $62.37^{* * *}$ & 8.24 & -1.58 & $23.86 \%$ \\
\hline $\mathbf{2 0 0 9}$ & 21.05 & 30.25 & 43.11 & -0.51 & $-0.06 \%$ \\
\hline $\mathbf{2 0 1 0}$ & 32.2 & 37.87 & 26.36 & -0.74 & $-0.97 \%$ \\
\hline $\mathbf{2 0 1 1}$ & 28.58 & -68.69 & 21.38 & $-6.97 * *$ & $5.49 \%$ \\
\hline $\mathbf{2 0 1 2}$ & -10.16 & 36.44 & 39.77 & -6.7 & $1.25 \%$ \\
\hline $\mathbf{2 0 1 3}$ & -13.57 & $110.86^{* * *}$ & 15.6 & -0.13 & $87.60 \%$ \\
\hline $\mathbf{2 0 1 4}$ & -39.29 & $33.33^{* * *}$ & 126.34 & -16.15 & $3.76 \%$ \\
\hline $\mathbf{2 0 1 5}$ & 90.03 & -37.76 & 1.16 & -0.07 & $-0.97 \%$ \\
\hline $\mathbf{2 0 1 6}$ & $-166.38^{* * *}$ & $197.76^{* * *}$ & $156.62 * * *$ & -4.41 & $18.26 \%$ \\
\hline
\end{tabular}

Tab.VI does not provide contrary evidence to the three conclusion drawn above, and it offers additional clues that dividend payout ratios have loose positive relationship with $\mathrm{P} / \mathrm{E}$ ratios since 4 out of 9 coefficients $\boldsymbol{\alpha}_{1}$ are significant and positive.

\section{CONCLUSION}

This article has specified some factors which are expected to influence $\mathrm{P} / \mathrm{E}$ ratios and then has conducted empirical study to test the relationship. By examining traditional Discount Dividend Models such as Gordon Growth Model and H-model, we identify three factors, which are dividend payout ratio, Beta coefficients and earnings growth rates. Then we collect data of all domestic stocks traded in Shanghai Stock Exchange, exclude unqualified ones and divide the remaining into groups $\mathrm{P} / \mathrm{E}$ ratios, dividend payout ratios and Beta of these stocks exhibit varying degrees of persistence over time but this kind of persistence is not observed in the case of earnings growth rates. However, growth rates presents present a pattern of comovements across different groups of stocks. Then we carry out regression analysis. Generally, the regression model has weak explanatory power and different groups of stock do not show similarity manifest enough to be described as a pattern. But this model also provides evidence that dividend payout ratio correlates positively and adjusted earnings growth rates correlates negatively with $\mathrm{P} / \mathrm{E}$ ratios. The negative relation from growth rates is contrary to what the GGM and H-model indicate. In our further study, we will modify methodology and attempt to construct more advanced models, such as logistic model, to better capture behavior patterns of $\mathrm{P} / \mathrm{E}$ ratios.

\section{ACKNOWLEDGMENT}

I would like to express my sincere gratitude to all those who helped me during the writing of this article. I gratefully acknowledge the help of my supervisor, Ms.Yang Suzhen, who has offered me valuable suggestions in the academic studies. Without her patient instruction, insightful criticism and expert guidance, the completion of this thesis would not have been possible. Finally I should like to express my 
gratitude to my beloved mother who has always unconditionally encouragement.

\section{REFERENCES}

[1] F.K. Reilly, F.T. Griggs, and W. Wong, "Determinants of the aggregate stock market earnings multiple," Financial Review, 1983, pp. 36-45.
[2] A. Kane, A.J. Marcus, and J. Noh, "The P/E Multiple and Market Volatility," Financial Analysts Journal, 1996, pp. 16-24.

[3] M. Gordon, "Dividends, Earnings, and Stock Prices The Review of Economics and Statistics," vol. 41, 1959, pp. 99-105.

[4] R.J. Fuller, and C.C. Hsia, "A Simplified Common Stock Valuation Model," Financial Analysts Journal, 1984, pp. 49-56.

[5] W. Sharpe, "Capital Asset Prices: A Theory of Market Equilibrium under Conditions of Risk," Journal of Finance, 1964, pp. 425-442.

[6] W. Beaver and D. Morse, "What Determines Price-Earnings Ratios?" Financial Analysts Journal, 1978, pp. 65-76. 